\title{
Penile Fracture-Report on Three Cases from Cape Coast, Ghana
}

\author{
Fiifi Assabill, Emmanuel Owusu Ofori*, Patrick Opoku Manu Maison, Alvin Asante-Asamani \\ Cape Coast Teaching Hospital, Cape Coast, Ghana \\ Email: ^emma2ofori@yahoo.co.uk
}

How to cite this paper: Assabill, F., Ofori, E.O., Maison, P.O.M. and Asante-Asamani, A. (2022) Penile Fracture-Report on Three Cases from Cape Coast, Ghana. Open Journal of Urology, 12, 146-156. https://doi.org/10.4236/oju.2022.122015

Received: November 11, 2021

Accepted: February 25, 2022

Published: February 28, 2022

Copyright $\odot 2022$ by author(s) and Scientific Research Publishing Inc. This work is licensed under the Creative Commons Attribution International License (CC BY 4.0).

http://creativecommons.org/licenses/by/4.0/ (c) (i) Open Access

\begin{abstract}
Introduction: Penile fracture is a urological emergency that occurs when the penis in an erect state suffers a blunt trauma resulting in a rupture of the tunica albuginea of either one or both corpora cavernosa. It is often caused by vigorous sexual intercourse, hence the incidence of penile fracture is under-reported. We therefore present our experience of the clinical presentation and surgical management of penile fracture. Presentation of Cases: We report three cases of penile fracture and all were diagnosed based on their clinical presentation and examination findings. The patients include two middle aged men and one young man, all with history of hearing a popping sound and experiencing sudden onset pain with detumescence of the penis. No radiological investigations were carried out. An emergency surgical repair was done for all patients. Discussion: All the patients had no urethral injury on presentation and underwent immediate surgical repair. The erectile and voiding function of each patient was preserved. Conclusion: The management of penile fracture involves early diagnosis and immediate surgical repair. Early intervention is necessary to preserve penile function.
\end{abstract}

\section{Keywords}

Penile Fracture. Tunica Albuginea. Corpora Cavernosa, Tunical Injury

\section{Introduction}

Penile fracture is a urological emergency that occurs when the penis in an erect state suffers a blunt trauma resulting in a rupture of the tunica albuginea of either one or both corpora cavernosa. It is usually caused by vigorous sexual intercourse when the penis strikes the pubic symphysis or perineum [1]. Other causes of penile fracture include rolling over onto an erect penis, masturbation, falling out of bed onto an erect penis and forceful flexion of the penis to achieve 
detumescence [2].

The incidence of penile fracture is under-reported mainly because it is often of a sexual cause and the associated shyness patients feel narrating the occurrence [3]. Penile fracture is mainly a clinical diagnosis based on its peculiar history and examination findings. Patients usually describe a snapping, popping or crackling sound heard followed by a mild-severe pain and sudden detumescence of the erect penis. On examination, the penile shaft is angulated. Haematoma usually forms in the Buck's fascia and is observed as a swelling with ecchymosis along the shaft of the penis. Blood observed at the urethral meatus may indicate a urethral injury [4].

In some circumstances where history and examination findings are inconclusive or a urethral injury is suspected, imaging modalities such as ultrasonography and colour doppler, MRI, cavernography, retrograde urethrography and angiography are employed [5]. The management of penile fracture is mainly surgical. Conservative management has been associated with many complications, hence it has fallen out of favour [6].

The objective of this study is to present our experience with the clinical presentation and surgical management of penile fracture. From 2018 to 2021, three patients were admitted to the urology unit of the Cape Coast Teaching Hospital on account of penile fracture. All the patients were diagnosed clinically based on their history and examination findings. History was taken with enquiry of the duration since the time of injury, cause of injury and symptoms experienced after injury. No imaging investigation was carried out. Surgical repair was done for each patient on the same day of presentation. All patients were placed under spinal anesthesia. A distal degloving subcoronal circumferential incision was made to explore both corpora and urethra. Haematoma was identified under the Buck's fascia. After incision and drainage of the haematoma, the tunical tear was identified. The affected corpora was toileted and the edges of the tunica refreshened. The laceration was sutured in interrupted fashion, with absorbable or non-absorbable suture and the suture knots buried. Gitte's test was done to confirm full closure of defect.

All patients were given prophylactic antibiotics. All patients were also counselled on abstinence from sexual activity for a minimum of 6 weeks to allow for complete healing of the wound. Patients were followed up for a minimum of 3 months (range between 3 months - 3 years) and assessment of their erectile and voiding function was done.

\section{Presentation of Cases}

\subsection{Case 1}

A 54-year-old man with no known medical condition, presented to the emergency room with a history of a sudden onset penile pain and swelling of about 6 hours duration. The patient reported to have heard a pop sound associated with a sudden detumescence of the penis after falling on an erect penis. The patient 
had no haematuria or voiding difficulty. On physical examination, the penile shaft was deformed and swollen with ecchymosis. No blood was seen at the penile meatus. The patient was clinically diagnosed with penile fracture. No imaging test was done. An emergency surgery was performed for the patient. At surgery, haematoma in Buck's fascia was identified and evacuated. A unilateral tunical tear measuring $1 \mathrm{~cm}$ was identified at the penoscrotal junction and repaired using an absorbable suture. No urethral injury was identified. The patient had an uncomplicated post-operative period and was discharged on post-operative day 7. No complications of voiding difficulty or erectile dysfunction were identified during the 3 years of follow-up with an uneventful recovery. Based on the International Index of Erectile Function (IIEF) score, the patient had a total of 28 out of 30 in the area of erectile function. This indicates no erectile dysfunction.

\subsection{Case 2}

A 60-year-old man with no known medical condition, presented to the emergency room with a history of penile swelling and pain of 12 hours duration. The patient was having sexual intercourse when he heard a pop sound associated with sudden pain and detumescence of the penis. There was no haematuria or voiding difficulty. On physical examination, the penis was angulated and swollen with ecchymosis. No blood was seen at the penile meatus. Penile fracture was diagnosed based on clinical presentation. No radiological investigations were done as no urethral injury was suspected from the history and examination. An emergency exploration and repair of tunical rupture was done. Intra-op findings included haematoma confined to the Buck's fascia and a unilateral tunical rupture located at the distal one-third of the penile shaft which measured about $1 \mathrm{~cm}$. No urethral injury was identified. Tunical rupture was successfully repaired using an absorbable suture. The patient had an uncomplicated post-operative period and was discharged on post-operative day 3. After 10 months of follow-up after surgery with an uneventful recovery, the patient had no voiding or erectile dysfunction. His IIEF score in the domain of erectile function was 28 , indicating no erectile dysfunction.

\subsection{Case 3}

A 31-year-old man with no known medical condition, presented to the emergency room with a history of pain and swelling of about 9 hours duration. Patient reports of having sexual intercourse in reverse coital position when he heard a pop sound and sudden onset pain with detumescence of the penis. On physical examination, the penile shaft was angulated and swollen as shown in Figure 1 but no ecchymosis was observed due to dark pigmented skin colour. The patient reported blood was seen from the penile meatus but had no difficulty voiding. Penile fracture was clinically diagnosed and the patient was sent to the theatre for emergency exploration and repair of tunical injury. Intra-operative findings included a haematoma confined in Buck's fascia and a $1.5 \mathrm{~cm}$ tear in the tunica which was identified as shown in Figure 2 and repaired using a 
non-absorbable suture (Figure 3). No laceration of the corpus spongiosum was observed. A urethral catheter was therefore inserted as a conservative management of the urethral injury. The contralateral cavernosum was explored but no tunical injury was identified. The patient had an uncomplicated post-operative period as shown in Figure 4 and was discharged 2 days after surgery. He had 3 months

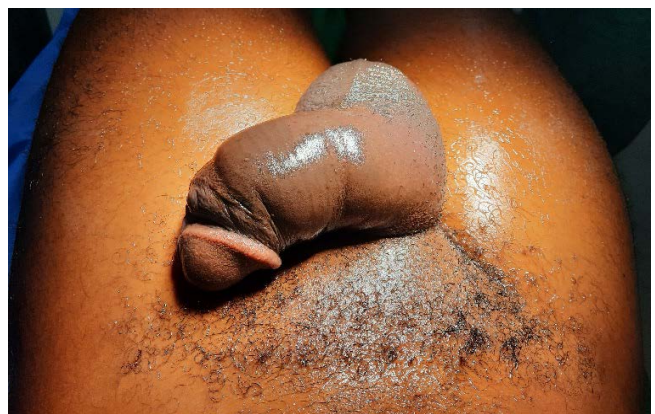

Figure 1. Swollen and deformed penile shaft (Picture by Dr Ofori).

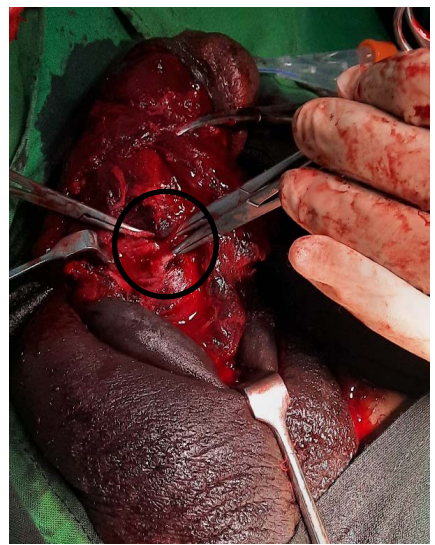

Figure 2. Tunica albuginea tear identified (Picture by Dr Ofori).

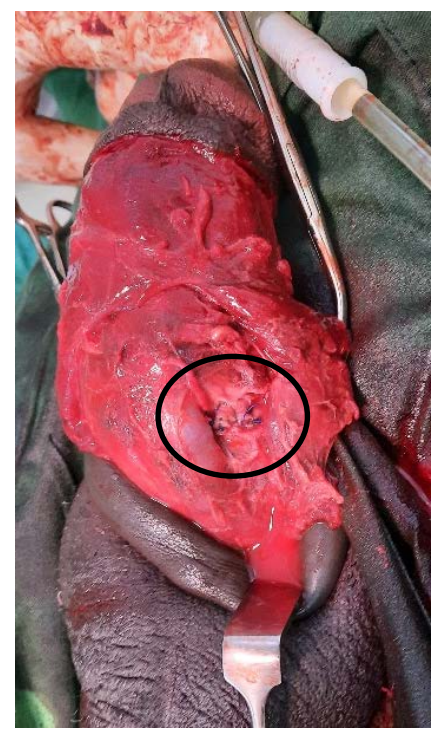

Figure 3. Tunical tear sutured (Picture by Dr Ofori). 


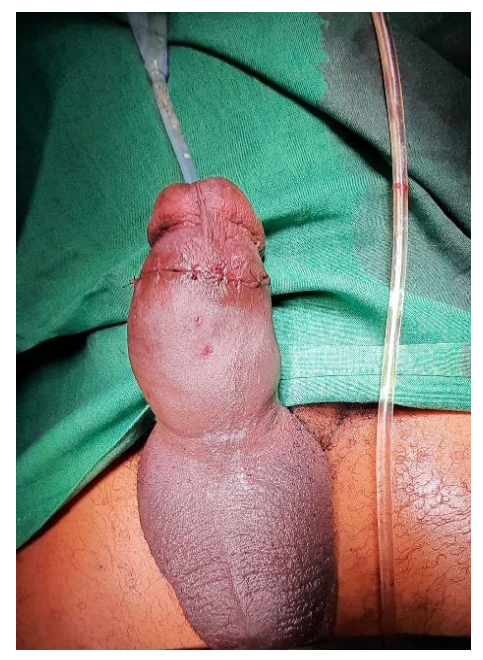

Figure 4. Skin incision sutured (Picture by Dr Ofori).

of follow-up with an uneventful recovery. No voiding or erectile dysfunction has been reported so far. Patient's IIEF score in the area of erectile function was 27 indicating no erectile dysfunction.

\section{Discussion}

In modern literature of medicine, the first published case of penile fracture was the article der fractura penis (German) of 1924 by Malis and Zur. Nonetheless, the earliest documentation of penile fractures dates back to a report by an Arabian physician over 10 decades ago [7].

Penile fracture is presumed to be a rare urological emergency but the true prevalence of the condition cannot be accurately ascertained in the clinical setting due to under-reporting of cases. As a result of socio-cultural perceptions surrounding the sexually related cause of the event, many feel embarrassed to report [8]. According to a study by Atat et al., penile fracture occurred within the age range of $12-82$ years and most of the patients were in their $4^{\text {th }}$ decade of life [9] [10]. In this study, the three patients were in their 6th, 7th and 4th decades respectively.

Penile fractures are associated with blunt trauma to an erect penis leading to a tear in the tunica albuginea of either one or both cavernosa bodies. The tear is usually unilateral, transverse and at the proximal end of the penis [11]. During an erection, the tunica albuginea is susceptible to tear as a result of a decrease in its thickness from $2 \mathrm{~mm}$ in a flaccid state to $0.25-0.5 \mathrm{~mm}$ in an erect state. Beyond a threshold intra-corporeal pressure of $1500 \mathrm{mmHg}$, the tunica loses its tensile strength leading to a rupture [12]. Blood extravasates from the deep artery of the cavernosa body into the Buck's fascia forming a haematoma. In the event where the Buck's fascia ruptures, extravasated blood collects in the Dartos fascia and may spread along its fascial plane into the lower abdominal wall where it is continuous with the Scarpa's fascia. Blood may spread into the scrotum within the Dartos fascia or the perineum where it is continuous with the 
Colles' fascia [13]. If the leaked blood is confined in the Colles' fascia, a "butterfly sign" may be seen [14]. From this study, haematoma was confined to the Buck's fascia in all three patients.

According to a meta-analysis done by Takir et al., $46 \%$ of cases of penile fracture were caused by sexual intercourse; making up the majority of cases. Forced flexion accounted for $21 \%$ of cases, followed by masturbation, $18 \%$ [1]. Out of the three cases reported in this study, two were caused by sexual intercourse. Although the reverse coitus position is widely known to be more likely to cause a penile fracture, it was insignificant $(\mathrm{p}=0.59)$ in the meta analysis of 5 different studies by Takir et al. [1]. One out of the three patients in this series had penile fracture in the reverse coitus position. In some countries in the Middle East such as Iran, forced flexion is practiced more often, and is known as "Taqaandan." According to a study by Zargooshi, $76 \%$ of males who practiced it suffered a penile fracture raising the prevalence of penile fracture within the region [15].

Penile fracture is usually diagnosed clinically because of its unique clinical presentation. Patients report of hearing a popping, cracking or snapping sound associated with sudden onset pain which may be mild, moderate or severe depending on the severity of the injury [6]. On physical examination, the penile shaft is seen to be swollen with ecchymosis. This presentation is called the "aubergine sign." The shaft of the penis is usually deformed in a direction opposite the site of injury. A "rolling sign" is also seen which is a discrete and fixed haematoma which is palpable as the skin is rolled over [4]. From our study, all the patients were diagnosed clinically using history and physical examination. They all attested to hearing a snapping sound associated with some pain and sudden detumescence. On examination, the penile shaft was swollen and ecchymosed. This observation is similar to results found by Amer et al., that showed that majority of patients presented with penile swelling and ecchymosis (45\% and 33\% respectively) [1]. In one patient, no ecchymosis was observed which was due to the darkened skin colour. The penis was angulated with its curvature away from the site of injury in all three patients.

A clinical diagnosis was made from the history and clinical examination which unequivocally suggested a penile fracture. For this reason, no further radiological investigations were conducted for the patients. Some studies indicated preference for radiological investigations prior to surgery to aid in localizing tear [16]. With the need for immediate surgical intervention, many others are of the viewpoint that such investigations are time-consuming with delays leading to poor-outcomes [8] and such imaging tests are only relevant when a urethral injury is likely or the clinical presentation is not clear hence the need for confirmation [3] [17].

Current management of penile fractures is surgery [5] [18] [19]. In the past, conservative management of penile fractures was the practice. Elastic bandages, cold compresses, antibiotics, anti-inflammatory agents, anticoagulants, fibrinolytics, erection suppression drugs like anti-androgens and estrogen analogues were used [20]. This practice was associated with high rates of complications of 
29\% - 53\% [21]. In 1936, Fetter and Gartmen first described the surgical repair of penile fracture. However, it gained popularity in the 1980's when several studies showed that surgical repair was associated with less complications [22]. A study by Muentener et al. revealed that immediate surgical intervention had a better outcome with $92 \%$ success rate as compared to 59\% for conservative management [23]. Studies by Amer et al., Gamal et al. and Zarin et al. also confirmed that surgical repair was superior to conservative management with less than $10 \%$ complication rate [1] [19] [24] [25]. Early surgical repair aims at relieving symptoms, preventing erectile dysfunction, ensuring normal voiding, reducing hospital stay while minimizing complications associated with delayed treatment such as permanent penile deformity and fibrosis [4].

In this study, all patients had an immediate surgical repair done. This mainly involved the identification and evacuation of haematoma, debridement and the repair of tunical laceration. The procedure was done under spinal anaesthesia. The surgical repair can also be done under general anaesthesia and even local anaesthesia [6] [8]. For all the patients in this study, a sub-coronal degloving incision was made to locate the haematoma and site of fracture. Many types of incisions have been described by different authors including longitudinal incision over the suspected haematoma, midline peno-scrotal incision over median raphe, para-penile incision, inguino-scrotal incision and infra-pubic incision [21] [26]. Nonetheless, the sub-coronal degloving approach offers the best cosmesis and provides an excellent exposure of both corpora cavernosa and the corpus spongiosum for easy identification and repair of tunical fracture and urethral injury [13] [27]. A distal circumferential sub-coronal incision is made and the skin degloved proximally to the penoscrotal junction. The corpora cavernosa are explored for identification and evacuation of haematoma. Bleeding vessels are ligated. The tunical laceration is identified and a local cavernosal debridement is done to remove dead tissue present [28]. In a series by Nawas et al., the orientation of the tear in the tunica albuginea in many cases is transverse and ventrally or laterally positioned at the proximal end of the penile shaft. That notwithstanding, the fracture can occur anywhere along the tunica [4]. Following toileting of the cavernosa, the tunical edges are freshened and sutured with either continuous or interrupted sutures. Absorbable or non-absorbable sutures can be used to close the tunical defect. Opinions are divided on the best choice as some argue that the use of non-absorbable sutures are associated with stitch granulomas, painful and palpable knots as well as stitch sinuses [29]. Proponents of the use of non-absorbable sutures in tunical defect closure believe it holds together the tunical edges in place for a long time preventing breakdown and recurrence of defect when intracorporeal pressure increases [27]. Absorbable sutures (vicryl) were used for repair of tunical defect in the first two patients in this series whilst a non-absorbable suture (prolene) was used in the third patient. After the tunical defect is sutured, the Gittes test (intracorporeal saline injection) is done to cause an artificial erection to help the surgeon identify any obscure tears that have not been sutured as well as assess the curvature of the penis in an erect state 
[30].

Urethral injury is sometimes associated with penile fractures and usually occurs at the same level of tunical injury [17]. When a urethral injury is suspected, the use of retrograde urethrogram is relevant to confirm and localize the urethral injury [8]. Management of urethral injury is usually by urethral stenting or an end-to-end anastomosis [13]. However, in mild injuries where voiding is achieved spontaneously, a urethral catheter is passed and kept in situ for 2 - 3 weeks to allow for the healing of the urethra. The reason urethroplasty may not be employed in this setting is to avoid a possible complication of stricture formation from the surgery [27]. In Case 3, despite the presence of blood at penile meatus, no laceration of the corpus spongiosum was observed which suggested that a rupture of the urethral wall was less likely. Hence, the blood seen at the meatus may have been due to a contusion in urethral mucosa. A urethral catheter was therefore inserted as a form of conservative management of the urethral injury.

Non-operative management accounts for most complications associated with penile fractures [31]. Such complications include erectile dysfunction, urethrocarvenous fistula, fibrosis with permanent penile deformity, painful erection, strictures, pulsative haematoma and penile necrosis [32] [33]. This is markedly reduced by early surgical repair. The repair of penile fractures is not devoid of possible complications. With the use of a degloving distal subcoronal circumferential incision, complications that may occur include transient penile oedema, neurovascular injury, abscess formation, subcoronal skin necrosis and infection [34].

A differential diagnosis for penile fracture is a pseudo penile fracture that occurs as a result of rupture to the dorsal artery or vein of the penis [35]. This may pose a diagnostic challenge as clinical presentation mimics a true penile fracture. The patient however does not hear the classic snap sound but experiences the sudden detumescence of the penis as seen in true penile fracture. That notwithstanding, the ultimate step in diagnosing a pseudo penile fracture is surgery where a rupture of either the superficial dorsal vein, deep dorsal vein, dorsal artery or a non-specific dartos bleed of the penis is identified with intact tunica albugenia and corpora cavernosa bodies. The ruptured vessels are then ligated at both ends to secure haemostasis [36] [37].

Patient should be advised to avoid sexual intercourse for 6 - 8 weeks to allow for complete healing of the fracture. Follow-up is relevant to identify post-operative complications.

\section{Conclusion}

Penile fracture is a urological emergency. Knowledge of the clinical presentation is necessary for rapid diagnosis and immediate intervention. Radiological investigations are not relevant except a urethral injury is suspected. Immediate surgical repair of fracture is recommended for managing penile fracture as it is associated with low rates of complications and the restoration of both erectile and 
voiding function of the penis.

\section{Consent}

All the patients provided written informed consent for the publication of this case series and the accompanying images.

\section{Ethical Approval}

Written informed consent was obtained from the patients for publication of this case series and the accompanying images.

Permission was also granted by the Health Monitoring and Evaluation and Research department of the Cape Coast Teaching Hospital for this study.

\section{Conflicts of Interest}

Authors have declared that no competing interests exist.

\section{References}

[1] Amer, T., Qazi, H., Wilson, R., et al. (2016) Penile Fracture: A Meta-Analysis. Urologia Internationalis, 96, 315-329. https://doi.org/10.1159/000444884

[2] Ateyah, A., Mostafa, T., Nasser, T. and Hadi, A. (2008) Penile Fracture: Surgical Repair and Late Effects on Erectile Function. The Journal of Sexual Medicine, 5, 1496-1502. https://doi.org/10.1111/j.1743-6109.2007.00769.x

[3] Mahapatra, R.S., Kundu, A.K. and Pal, D.K. (2015) Penile Fracture: Our Experience in a Tertiary Care Hospital. The World Journal of Men's Health, 33, 95-102. https://doi.org/10.5534/wjmh.2015.33.2.95

[4] Nawaz, H., Khan, M., Tareen, F.M. and Khan, S. (2010) Penile Fracture: Presentation and Management. Journal of College of Physicians and Surgeons Pakistan, 20, 331-334.

[5] Gulmi, F.A. (2018) Penile Fracture. Reviews in Urology, 20, 41-42.

[6] Katswere, J.P., Bahloul, A., Hounsou, R., Todalehou, S. and Dieu, G. (2019) Diagnostic and Management of Penile Fracture: A Literature Review. The Journal of Medical Research, 5, 162-164. https://doi.org/10.31254/jmr.2019.5407

[7] Malis, J. (1924) Zur Kausuistik der fractura penis. Archiv Klinisch Chirurgie (German), 129, 651 .

[8] Wani, I. (2008) Management of Penile Fracture. Oman Medical Journal, 23, 162-165.

[9] El Atat, R., Sfaxi, M., Benslama, M.R., Amine, D., Ayed, M., Mouelli, S.B., et al. (2008) Fracture of the Penis: Management and Long-Term Results of Surgical Treatment. Experience in 300 Cases. Journal of Trauma and Acute Care Surgery, 64, 121-125. https://doi.org/10.1097/TA.0b013e31803428b3

[10] Koifman, I., Cavalcanti, A.G., Manes, C.H. and Filho, D.R. (2003) Penile Fracture: Experience in 56 Cases. International Brazilian Journal of Urology, 29, 35-39. https://doi.org/10.1590/S1677-55382003000100007

[11] Waseem, M., Upadhyay, R., Kapoor, R. and Agyare, S. (2013) Fracture of the Penis: An Atypical Presentation. International Journal of Emergency Medicine, 6, 32. https://doi.org/10.1186/1865-1380-6-32 
[12] De Rose, A.F. and Giglio, M. (2001) Traumatic Rupture of the Corpora Cavernosa: New Physiopathologic Acquisitions. Urology, 57, 319-322. https://doi.org/10.1016/S0090-4295(00)00926-2

[13] Sawh, S.L., O’Leary, M.P., Ferreira, M.D. and Berry, A.M. (2008) Fractured Penis: A Review. International Journal of Impotence Research, 20, 366-369. https://doi.org/10.1038/ijir.2008.12

[14] Gottenger, E.E. and Wagner, J.R. (2000) Penile Fracture with Complete Urethral Disruption. Journal of Trauma and Acute Care Surgery, 49, 339-341. https://doi.org/10.1097/00005373-200008000-00025

[15] Zargooshi, J. (2009) Sexual Function and Tunica Albuginea Wound Healing Following Penile Fracture: An 18-Year Follow-Up Study of 352 Patients from Kermanshah, Iran. The Journal of Sexual Medicine, 6, 1141-1150. https://doi.org/10.1111/j.1743-6109.2008.01117.x

[16] Chahal, A., Gupta, S. and Das, C. (2016) Penile Fracture. BMJ Case Reports, 2016, Article ID: 215385. https://doi.org/10.1136/bcr-2016-215385

[17] Kamdar, C., Mooppan, U.M. and Kim, H. (2008) Penile Fracture: Preoperative Evaluation and Surgical Technique for Optimal Patient Outcome. Discussion 1644. BJU International, 102, 1640-1644. https://doi.org/10.1111/j.1464-410X.2008.07902.x

[18] Agarwal, M.M., Singh, S.K., Sharma, D.K., Ranjan, P., Chandramohan, V., et al. (2009) Fracture of the Penis: A Radiological or Clinical Diagnosis? A Case Series and Literature Review. The Canadian Journal of Urology, 16, 4568-4575.

[19] Gamal, W.M., Osman, M.M., Hammady, A., Aldahshoury, M.Z., Hussein, M.M. and Saleem, M.M. (2011) Penile Fracture: Long-Term Results of Surgical and Conservative Management. The Journal of Trauma Injury Infection and Critical Care, 71, 491-493. https://doi.org/10.1097/TA.0b013e3182093113

[20] Kalash, S.S. and Young, J.D.J. (1984) Fracture of Penis: Controversy of Surgical Versus Conservative Treatment. Urology, 24, 21-25. https://doi.org/10.1016/0090-4295(84)90380-7

[21] Gregory, S., Jack, M., Garraway, I. and Reznick, R. (2004) Current Treatment Options for Penile Fracture. Reviews in Urology, 6, 114-120.

[22] Derouiche, A., Belhaj, K., Hentati, H., Hafsia, G., et al. (2008) Management of Penile Fractures Complicated by Urethral Rupture. International Journal of Impotence Research, 20, 111-114. https://doi.org/10.1038/sj.ijir.3901599

[23] Muentener, M., Suter, S., Hauri, D., et al. (2004) Long-Term Experience with Surgical and Conservative Treatment of Penile Fracture. The Journal of Urology, 172, 575-579. https://doi.org/10.1097/01.ju.0000131594.99785.1c

[24] Zarin, M., Haider, K., Aurangzeb, M., et al. (2006) Surgical Treatment of Fractured Penis. Journal of Surgery Pakistan, 11, 107-109.

[25] Mensah, J.E., Morton, B. and Kyei, M. (2010) Early Surgical Repair of Penile Fractures. Ghana Medical Journal, 44, 3-6. https://doi.org/10.4314/gmj.v44i3.68898

[26] Patel, A. and Kotkin, L. (2010) Isolated Urethral Injury after Coitus-Related Penile Trauma. The Journal of Trauma, 68, 89-90. https://doi.org/10.1097/TA.0b013e31818d0e2d

[27] Satyendra, P., Maliza, P., et al. (2019) Fracture of the Penis: A Review. EMJ Reviews, 7, 83-88.

[28] Prajapati, D.K., Rampal, K., Ali, I., Rangera, M., Chaursia, S., et al. (2016) Penile Fracture and Its Management. International Surgery Journal, 3, 1714-1717. 
https://doi.org/10.18203/2349-2902.isj20163552

[29] Ali, M.Z., Swati, M.J., Ali, F.Z., et al. (2007) Fracture of the Penis: A True Surgical Emergency. International Journal of Surgery, 13, 201-209.

https://doi.org/10.5580/15c9

[30] Gittes, R.F. and McLaughlin 3rd, A.P. (1974) Injection Technique to Induce Penile Erection. Urology, 4, 473-474. https://doi.org/10.1016/0090-4295(74)90025-9

[31] Mustafa, G., Necip, P., Ilhan, G., Kerem, T., Kürsat, C., et al. (2012) Our 8 Years Experience on Penile Fractures: The Diagnosis and Treatment. Journal of Clinical and Analytical Medicine, 3, 429-431.

[32] Dorde, N. and Mićić, S. (2007) Pulsative Hematoma-A Penile Fracture Complication. Vojnosanitetski Pregled, 64, 58-60. https://doi.org/10.2298/VSP0701058D

[33] Mydlo, J.H. (2001) Surgeon Experience with Penile Fracture. The Journal of Urolo$g y$, 166, 528-529. https://doi.org/10.1016/S0022-5347(05)65975-7

[34] Minns, A.B. and Yafai, S. (2011) Penile Fracture in a Patient Presenting with Groin Pain. Journal of Emergency Medicine, 40, 441-442. https://doi.org/10.1016/j.jemermed.2008.08.005

[35] Bar-Yosef, Y., Greenstein, A., Beri, A., Lidawi, G., et al. (2007) Dorsal Vein Injuries Observed during Penile Exploration for Suspected Penile Fracture. The Journal of Sexual Medicine, 4, 1142-1146. https://doi.org/10.1111/j.1743-6109.2006.00347.x

[36] Feki, W., Derouiche, A., Belhaj, K., et al. (2007) False Penile Fracture: Report of 16 Cases. International Journal of Impotence Research, 19, 471-473. https://doi.org/10.1038/sj.ijir.3901574

[37] Kurkar, A., Elderwy, A.A. and Orabi, E. (2014) False Fracture of the Penis: Different Pathology but Similar Clinical Presentation and Management. Urology Annals, 6, 23-26. https://doi.org/10.4103/0974-7796.127015 